\title{
Seeing Beyond Anatomy: Quality of Life with Geographic Atrophy
}

\author{
Dolores Caswell · William Caswell · Jill Carlton (iD
}

Received: April 6, 2021 / Accepted: May 12, 2021 / Published online: June 5, 2021

(c) The Author(s) 2021

\begin{abstract}
Quality of life (QoL) is a complex idea without a clear consensus definition. Generally speaking, QoL refers to several subjective measures of wellbeing that vary by individual and circumstance. QoL can decline noticeably as a disease progresses. This is particularly true for geographic atrophy (GA), an advanced form of agerelated macular degeneration. GA leads to vision loss for which there is no currently approved pharmacological treatment. There is a lack of qualitative, patient-driven research on QoL in GA. There is also limited information
\end{abstract}

Patient author: Dolores Caswell and Carer author: William Caswell.

Supplementary Information The online version contains supplementary material available at https:// doi.org/10.1007/s40123-021-00352-3.

D. Caswell

Canadian National Institute for the Blind, Toronto, Ontario, Canada

D. Caswell

Patient author, Vancouver, British Columbia, Canada

W. Caswell

Carer author, Vancouver, British Columbia, Canada

J. Carlton $(\square)$

School of Health and Related Research, University of

Sheffield, Sheffield, UK

e-mail: j.carlton@shef.ac.uk available to both patients and physicians about GA, existing support groups and available assistive technologies. To address this, we have collated the experiences of a person with GA and those of her partner and carer with the current literature on QoL in GA. We have also outlined some of the wide range of developing technologies available to help people with GA carry out daily tasks and hobbies. It is clear that support, whether through informal or structured care, is vital to the wellbeing of people with GA. Despite this, the general public are often unaware of care work, which may result in this integral role being undervalued and under acknowledged. Furthermore, it is apparent that the general public have fundamental misunderstandings around what vision loss entails and are unaware that blindness is a vast spectrum. This feeds into the seemingly paradoxical mix of isolation and dependence on others that often results from GA and vision loss. Through this qualitative examination of a patient's experiences, we hope to inform and educate both patients and physicians about GA as well as precipitate discussion around the frameworks that should be in place to support both newly diagnosed and long-term patients with GA and other retinal diseases. 


\section{PLAIN LANGUAGE SUMMARY}

Asking someone about their 'quality of life' is one way to understand their general wellbeing. Quality of life can mean different things to different people. For some people it may mean being able to do what they want to. For others it may include feelings such as happiness. Diseases that cause people to lose their vision can have a very big impact on quality of life. Geographic atrophy is an eye disease that leads to loss of vision and has no cure. In this article, Dolores, a person with geographic atrophy, Bill, her husband and carer, and Jill, a quality of life researcher, discuss how geographic atrophy can change quality of life. Vision loss often means that people are unable to keep up their hobbies and do daily tasks, like shopping or cooking. Learning to use smartphone apps and gadgets can help many people with their hobbies and tasks. Feeling alone also makes quality of life for people with geographic atrophy worse. The help and understanding of others-including friends, family and doctors-are very important. Treatment plans for patients with vision loss need to consider all parts of a patient's life. Training for doctors should continue to emphasise that people with geographic atrophy are more than just eyes that cannot be treated.

Keywords: Age-related macular degeneration; Geographic atrophy; Patient perspective; Qualitative; Quality of life; Retina

\section{Key Summary Points}

Geographic atrophy (GA) is an eye disease that leads to irreversible vision loss, with no currently approved pharmacological treatment.

There is a lack of qualitative, patientdriven research on quality of life (QoL) in patients with GA.

To address this, three people-a person with GA, her partner and carer, and a QoL researcher-have collated their experiences alongside some of the current literature on QoL in GA.

We found that although the support of others and use of assistive technologies are vital to the QoL of people with GA, many people are unaware or unable to access these resources.

The development of integrated care frameworks that consider the patient holistically will be critical to improving and preserving patient QoL in the future.

\section{DIGITAL FEATURES}

This article is published with digital features, including a summary slide, video and slide deck, to facilitate understanding of the article. To view digital features for this article go to https://doi.org/10.6084/m9.figshare.14573511.

\section{INTRODUCTION}

\section{What is Quality of Life?}

Quality of life (QoL) does not have a consensus definition and is recognised to be a complex concept [1]; although there are a number of definitions for QoL, they are not universally agreed. QoL can be defined using a range of 
domains, including psychological wellbeing and happiness, life satisfaction, physical health and function, and social role and expectations. The World Health Organization defines QoL as "an individual's perception of their position in life in the context of the culture and value systems in which they live and in relation to their goals, expectations, standards and concerns" [2]. Karnofsky outlined QoL in patients with cancer as a "patient's subjective improvement in terms of mood and attitude; general feelings of wellbeing; and activity, appetite, and the alleviation of distressing symptoms, such as pain, weakness, and dyspnea" [3]. Spitzer's Quality of Life Index is a tool that was developed in 1981 to assess QoL health outcomes in patients with chronic disease and states that QoL variables "should include physical, social, and emotional function; attitudes to illness; personal features of patients' daily lives, including family interactions; and the cost of illness" [4]. Some health agencies (such as the US Center for Disease Control and Prevention) use the term 'health-related quality of life', also known as HRQoL, which specifically refers to the aspects of QoL that have been shown to directly affect physical or mental health [5]. In older populations ( $\geq 65$ years), key QoL themes include maintaining social relationships, the ability to undertake hobbies, good health and mobility, and independence [6]. Ultimately, QoL refers to a highly subjective measure of patient happiness and may vary by individual and circumstance [6].

In addition to the lack of a concrete definition, there are challenges regarding how to specifically measure and interpret QoL. Physicians often radically underestimate the effect of visual impairment on QoL [7]. Despite this, most measures of QoL are based on the opinions of physicians rather than the opinions of people for whom QoL is measured, limiting their relevance to patients [8]. In response to this problem, an emerging set of questionnaires are being developed that use a 'bottom-up' design based on patient input [9]. Bottom-up questionnaires tend to use more appropriate and less clinical language and contain measures that are considered relevant to patients [9]. The validity of content is one of the most important properties of tools that measure patient-reported outcomes: the COSMIN methodology for assessing content validity includes criteria on content relevance, comprehensiveness and comprehensibility for patients [10]. Furthermore, the Food and Drug Administration (FDA) guidelines for the development of patient-reported outcome instruments (currently under consultation) emphasise the importance of patient engagement and patient comprehension when creating tools to measure QoL [11]. However, FDA guidelines also specify internal consistency as one of their essential criteria for the approval of patient-reported outcome instruments [12]; some patient population-based measures, such as the World Health Organization Quality of Life Instrument-Older Adults Module (WHOQOL-OLD), have failed to meet internal consistency criteria, which may limit their use as quantitative tools in research [8]. When dealing with approved tools used to measure QoL, both the qualitative and quantitative aspects must be considered.

Interest in QoL research has increased with time: in a PubMed search of publications in 2013 including the term 'quality of life', there were approximately 4000 results [13], whereas in 2020 there were over 33,000 results (searches performed on 1 February 2021). Increased interest in QoL may reflect a growing awareness that clinical outcomes do not always reflect or resonate with patient outcomes and expectations. It is clear that QoL is a rapidly growing field and will yield important insights into patient wellbeing as the quantity of research expands.

\section{What is Geographic Atrophy?}

Geographic atrophy (GA) is an advanced form of age-related macular degeneration (AMD) that is also known as advanced 'dry' AMD [14]. GA leads to progressive, and at present irreversible, loss of vision [14]. Vision loss is caused by the death of photoreceptors, which are specialised cells in the retina that convert light energy into visual signals $[15,16]$. Photoreceptor death is accompanied by loss of the retinal pigment epithelium and the choriocapillaris, which 
regulate the photoreceptor layer and supply oxygen to the retina [17-19]. GA affects around 5 million people globally and accounts for roughly one-quarter of legal blindness in the USA and the UK $[17,20]$.

GA has quite a variable clinical presentation, but often begins as a single lesion in the outer fovea [21]. The fovea is a region of the retina that is responsible for detailed vision and has a high density of photoreceptors [22]. Thus, damage to the fovea reduces one's ability to see clearly. Anatomical changes in the eye, such as the presence of drusen (small yellow-white lesions), are also associated with AMD; their presence increases the risk of progression to GA $[23,24]$. Inflammation is also thought to play a key role in the development of GA, though the exact mechanism is unclear [14, 17, 25]. Although there are lifestyle changes that a patient can make to reduce the risk of developing GA or to slow its progression, such as quitting smoking or taking nutritional supplements [26], there is currently no approved treatment for GA.

\section{How Does Geographic Atrophy Affect Quality of Life?}

GA has a profound effect on QoL, which can be quantitatively assessed using patient questionnaires or patient-reported outcome measures. The effect of GA on QoL is comparable to that reported among patients with advanced prostate cancer or severe cerebrovascular accident and worse than that reported among patients with chronic obstructive pulmonary disease or AIDS [7, 27]. Despite this heavy burden for patients, many physicians may underestimate the impact of GA on QoL. One study quantified the effect of AMD on QoL using 'utility value' a number representing the proportion of one's life expectancy that a person would willingly trade in order to return to normal health [7]. The study compared these values for patients with AMD against those of their treating physicians (who were asked to imagine that they had AMD). Patients with advanced AMD reported that they would trade an average of $60 \%$ of their remaining life expectancy to return to normal health [7]; their treating physicians underestimated this number by up to $97 \%$ [7].

GA is associated with a reduction in independence and mental wellbeing. Larger areas of GA are associated with decreased visual acuity, hindering the ability to carry out daily tasks [28-31]. GA also reduces one's ability to recognise faces [32, 33], and reading speed decreases as the GA lesion increases in size [31, 34]. Critically, GA severely impacts a patient's ability to drive, which limits their freedom to travel, reducing their independence [35]. Both AMD and GA increase the risk of depression and susceptibility to falls and injuries as a result of poor visual acuity [20]. Patients with GA have reported frustration about their lack of independence as well as needing to seek help from others [29].

There is relatively little qualitative research focusing on the effects of GA on QoL from a patient's perspective. Furthermore, commonly used measures of QoL in GA may not be relevant to the lived experiences of patients, as much of the focus is on measures of visual function rather than experience of life beyond vision. Some standardised questionnaires, such as the Impact of Vision Impairment (IVI) questionnaire, do include measures beyond visual function: the IVI comprises three subscales: 'reading and accessing information', 'mobility and independence' and 'emotional wellbeing' [36]. However, many questionnaires use absolute numerical scales, which may not be interpreted in the same way by all patients and may not reflect the day-to-day variability of their QoL. In addition, daily questionnaires for longterm QoL assessment have not been well examined, and therefore may be unsuitable for tracking QoL changes over time.

An alternative and potentially more relevant way of examining the impact of disease on someone's QoL is simple-ask the person directly. To address the relative paucity of qualitative information on what it is actually like to live with GA and to care for someone with GA, we-a person with GA (Dolores Caswell), her husband and carer (William Caswell, henceforth referred to as Bill) and a QoL researcher (Jill Carlton)- have worked together to interweave personal perspectives and 
experience with a review of current literature on QoL in GA. These conversations are organised into different themes, ranging from diagnosis to expectations of future treatment. Through this qualitative examination of GA, we hope to inform and educate patients about what to expect after a GA diagnosis and the types of help that are available and to outline the current unmet needs facing patients with GA.

\section{A PATIENT PERSPECTIVE ON GA}

Dolores Caswell was diagnosed with GA in 2014 and is based in Canada. She has recently moved from Kelowna, BC, to Vancouver, BC, with her husband. The following section is driven by her experiences with GA (in italics) and supported by the scientific literature on vision loss, QoL and GA.

\section{My Experience of GA}

\section{Hope I'm at the Plateau of Visual Loss, but I Don't Know}

GA is a chronic and progressive disease whereby damage to the retina gradually reduces the ability to see over time [37]. However, despite its known effect on vision, changes in visual acuity as measured using traditional optician's eye charts do not correlate well with GA progression [38]. Alternative measures of visual function (such as the ability to see differences in brightness levels, also known as 'contrast sensitivity') are very important to QoL in GA [39]. These measures diminish as GA progresses, even when 'normal' visual acuity is maintained [40]. Research also indicates that the spread of GA is faster in the periphery than in central vision [38].

For me personally, a good day is sunny, and light makes a huge difference. Shadows and greyness make the day worse because they affect the contrast between objects, people and scenery. I find that my vision has become hazy in the periphery as my GA has progressed. I feel some uncertainty around the future of my vision, as I believe there has been a lot of damage to my retina-I am not sure whether any future treatments could help me and my vision.

Being able to understand and anticipate changes in vision beyond simple visual acuity is very important to fully understand GA. It is clear that some patients lack information around their expected prognosis; this may be due to the lack of currently available treatments, which leads ophthalmologists to discharge patients upon diagnosis with little further advice. The initial shock of diagnosis may prevent patients from effectively absorbing information about their condition. Furthermore, discharged patients who are not routinely seen at clinics do not receive updated information about their condition or new treatment options. Providing patients with more knowledge about the underlying cause of their GA may assist in managing expectations about how their vision may change over time. In addition, systematic follow-up care could ensure that all patients are able to understand their condition and its prognosis.

\section{Blindness is a Word that Confuses People}

I feel that most people truly do not understand what blindness is, and believe that being legally blind means that you are totally blind; you have to explain yourself over and over again. I worry that people think that if I walk past them without saying anything I must be snooty, whereas the truth is that I am unable to recognise them.

Up to $42 \%$ of all people with GA are classified as legally blind [20,41]. Despite the cultural understanding of blindness typically meaning 'unable to see', from a scientific perspective legal blindness refers to a visual acuity of 20/200 (EU equivalent 6/60) or worse in the better seeing eye, which is the equivalent of seeing at 20 feet what someone with 'normal' visual acuity could see at $200 \mathrm{ft}$ (or seeing at $6 \mathrm{~m}$ what someone with normal visual acuity could see at $60 \mathrm{~m}$ ). An alternative definition of legal blindness that is sometimes used is an eye chart measurement of 20/400 (EU equivalent $6 / 120)[20,41]$. Visual ability is not constant across the retina, and a person may have trouble 
with peripheral vision but still have central vision or vice versa [42].

General lack of understanding around what the word 'blindness' means can also lead to confusion about how best to address the vision problems that result from GA. Although magnification (using a hand-held glass, spectacle magnifiers or a $2-10 \times$ telescope) is commonly used to help address vision problems [43], it is not always useful for people with GA.

I find that as my GA has advanced, magnification just blurs everything. However, because magnification works for other people with macular degeneration that I know, other people assume that it will work for me too. Contrary to common knowledge about magnification, I find that smaller print is better than the large cards and large print that people typically use to increase accessibility for those with vision problems.

The language used to discuss GA is also important when it comes to improving general understanding: terms like 'vision loss' may be more informative than 'blindness'. Furthermore, it is clear that the standard tools used in public spaces to improve accessibility for those with vision loss may not be suitable for people with GA and that alternative options should be explored.

\section{There Were Times When I looked at a Person and Their Nose Would Relocate to Another Part of Their Face}

People who have vision loss may experience unexpected side effects, including visual hallucinations-known as Charles Bonnet syndrome. The symptoms of Charles Bonnet syndrome vary from simple geometric figures to animals in motion [44] and may be associated with larger areas of GA [44].

Personally, I found my experience of Charles Bonnet syndrome more interesting than frightening, but it may have helped that I was told about it being a potential side effect during my prior participation in a clinical trial.

Some people do find the hallucinations frightening: close to $30 \%$ of people report experiencing some distress as a result of the hallucinations, and they are more likely to occur for people who live alone [44, 45]. In addition, people may feel reluctant to discuss symptoms such as hallucinations due to fear of being considered 'senile'; therefore, the prevalence of Charles Bonnet syndrome may be higher than that reported in the literature.

Providing a clear explanation for these hallucinations has been shown to relieve the anxiety associated with their presence [46]; this demonstrates the importance of targeted patient information for improving mental health, and therefore QoL [46]. The need to provide such information extends to treating physicians, many of whom are unfamiliar with Charles Bonnet syndrome [46]. Better education around the possible side effects associated with GA could greatly reduce the anxiety associated with vision loss.

\section{The Impact of GA on My Quality of Life}

\section{Despite Bill Being Beside Me Now, I Cannot See} His Face: It's All in Shadow

GA has a substantial effect on the ability to recognise faces, and the impact becomes more noticeable as the disease progresses [29, 32]. The ability to recognise faces is central to social interaction; in young adults particularly, reduced facial recognition ability is associated with increased social anxiety [47].

I am a very social person, and the one thing that bothers me the most is that I can't see people clearly -if I stand very, very close, I can hold their face in my hands and peer at themthen I can see. But of course, I can't do that to just anyone. The fact that I cannot see faces clearly is one thing that really disturbs me.

The lasting emotional and social impact of not being able to clearly see your loved ones is unclear, but there is no doubt that it causes at least some level of distress.

\section{All My Hobbies Have Pretty Well Disappeared} People with 'low vision' are often concerned about their reduced ability to read; one study showed that $66.4 \%$ of people who had scheduled a low-vision appointment in the USA were 
worried about their reading ability [48]. However, $<10 \%$ of people with low vision are concerned about their reduced ability to partake in hobbies more generally [48], which suggests that for people with low vision (as opposed to GA), loss of hobbies is not an issue of note. It is not surprising that research indicates that the hobbies of people with GA may be affected to a greater degree than those of the general low vision population: half of all subjects in one study of people with GA reported that GA had a negative impact on hobbies and leisure activities-a much higher proportion than that reported in the general low-vision population [30]. Fortunately, some existing hobbies can be adapted for low vision-for example, other people have reported using digital technology such as eBook readers to magnify book text or devising clever methods of fishing that use the sense of touch rather than sight [29].

Personally, I find that with GA, my ability to take part in hobbies has been noticeably reduced. Although I can play golf with someone watching the ball for me, knitting and alternative art are no longer possible-I used to be an artist and I miss art. Since my diagnosis, I don't have any new hobbies, none at all. Hobbies never last forever, but when you have GA they stop earlier than you thought they would.

Many people with GA find that they can no longer enjoy their hobbies; better education around assistive technologies that are currently available, and specific techniques that can be learnt, may prolong the amount of time people can continue with their hobbies and could greatly improve QoL.

\section{I'm More Isolated, I Have to Depend on Others}

GA has a substantial effect on an individual's mobility and independence $[35,49]$. One of the main reasons for reduced independence for people with GA is its effect on the ability to drive; over half of all people with GA who have a valid driving licence do not feel confident driving during the day and the majority would not drive at night [35]. In one study, $66.7 \%$ of people diagnosed with GA became ineligible to drive within a median time of 1.6 years [20].
Many people with GA report not being able to drive as one of the key factors that reduces their QoL and independence $[29,30]$.

I feel strongly that my quality of life has gone down because I don't drive: it has taken away my independence. Another thing that worries me is being taken advantage of financially. When we sold our house recently, I couldn't read any of those forms and I had to really trust my partner. There is no such law in Canada that would mean my signature would not be legal if it hadn't been witnessed-there should be.

Despite that fact that many people with vision loss have to depend on others far more than those without vision loss, feelings of loneliness are common [50]. Depression and anxiety are not significantly associated with general AMD [51], but up to $25 \%$ of people with severe vision loss from AMD (such as GA) may experience depression [52], and the incidence of depression is strongly associated with the severity of vision loss [53].

Although we have a lot of good friends, I think we are maybe not included in the same way, as I can't do a lot of the things they do; new friends just don't understand, they're busy with their own lives and don't have the time to bother with someone who is disabled. The effect $G A$ has on independence can be an isolating experience, as you feel like you're separate from your family and friends, while depending on them to complete daily tasks like shopping or travelling. Even your personal finances may require support from someone else.

Independence and social interaction are very important for mental wellbeing. It is very important to ensure that people with GA are able to access the support of others when needed, but also that they are aware of the different ways in which they can carry out their daily tasks without the need for outside help.

\section{Feel Vulnerable When I Have My Cane, I Feel Different}

The white cane is a worldwide symbol for vision impairment and plays a key role in allowing 
people with vision loss to navigate independently $[54,55]$. However, the white cane may also cause people to feel self-conscious and family members to become overprotective [56]. Feelings of shame or embarrassment may be particularly pronounced when encountering people who knew them before the onset of vision loss [55]. Importantly, research has shown that there is a lack of well-described protocols and studies on how to train and orientate people on the use of a cane [57].

I find that if I have my cane, it makes a huge difference, and most people are very considerate. I should be using the cane more than I do, but the cane makes me feel vulnerable. I was first told about canes by someone who specifically told me that you are vulnerable with the cane and that has stuck with me.

Producing high-quality guidelines on how to introduce canes to patients (for physicians) and how to use canes for independence and mobility (for people with low vision) may be an effective way to restore some degree of confidence and independence for people with GA.

\section{Somewhere Along the Line It Gives You Strength, if You Want It}

I do not want people to feel as though there is no hope or joy for people with GA-I am a happy person and optimistic. While I miss the hobbies I used to have, it doesn't make me sad-I was just very lucky I was able to do them when I could. I think it hardens you in a sense, when you lose a sense-and I have found that my memory has improved because I have to memorise so many things.

Although there is little to no research on the effect of vision loss on working memory in older populations, research has indicated that children with vision loss have a higher working memory capacity than children without vision loss [58].

The support from my family and my husband, Bill, has been great, but I do think that it's very sad for people who are alone, and very hard.

It is clear that for people in isolation, dealing with vision loss is challenging and feelings of loneliness are common [50]. Creating systems that support people and provide independence for those without close family or friends could greatly increase the QoL of specific populations.

\section{My Experience of Clinical Research and Expectations of Future Treatment}

Several years ago, Dolores Caswell took part in a clinical trial for a (now terminated) potential treatment for GA [59]. This trial examined the effect of lampalizumab on patients with GA but was terminated as it did not meet its primary endpoint of reducing mean change in GA lesion area. This next section discusses the impact of clinical trials on a participant's QoL, driven by Dolores' personal experiences (in italics) and supported by the scientific literature.

\section{It Was a Good Experience, It Was Just Unfortunate that It Was Not the Answer}

Although there is limited research on why people choose to participate in clinical trials, or on the effects of clinical trials for patients beyond treatment, one survey has found that most people participate because they would like to contribute more to science (69\%) and/or learn more about their condition (51\%) [60]. Sixty-five per cent of people reported feeling more educated about their overall health as a result of trial participation, improving their QoL [60].

I learned a lot from taking part in the clinical trial. The trial helped me connect with a number of people who had helpful information and advice about technology that I could use to improve my QoL. However, for people with GA without such connections, from the time they are diagnosed, they basically don't have any help. Unfortunately, the trial stopped suddenly, saying that the results were inconclusive, and $I$ received no further information. Personally, I am also concerned about the hereditary aspects of $G A$, as I'd hate to pass this on to my children. I do worry any time my family say that their eyes are changing drastically, although I think they all know to ask their ophthalmologist to look into AMD or GA. 
Although GA is not a 'classic' inherited condition, there are some genetic risk factors for the development of GA, most notably a polymorphism in the ARMS2 (age-related maculopathy susceptibility) gene [61].

Overall, it is fairly uncommon for patients to be notified of clinical trial results, whether positive or negative, unless it is considered to influence their future care, despite clinical trial participation often requiring a substantial time investment on the part of the participant [62]. Although clinical trial participation may facilitate access to information and support, it should not be a prerequisite. It is vital to provide patients with a platform through which they can access information about GA and ongoing research without necessitating their participation.

\section{Would Worry About Surgery Unless It Was The Final Answer}

The range and type of treatment options are important to patient QoL. If patients are happy with the method of treatment administration, they are likely to take the treatment regularly [63]-missing treatments for vision loss can result in irreversible damage, and thus irreversible loss of QoL. That said, research shows that people with vision loss typically prioritise maintaining their vision over concerns about treatment type or frequency [64].

Although there is currently no treatment for $G A, I$ think I would feel safer with an injection because I would know that I was receiving the right dose. However, an oral compound would be easier and less invasive and would have less impact on my QoL. When I received injections in my eye during the clinical trial, the inconvenience of it all had an impact on my life. I feel that if they could have maintained my vision 6 years ago, it would have been wonderful, and if there was anything that could improve my eyesight, we would do itregardless.

As more treatments for AMD (the underlying disease that can lead to GA) emerge, patients and their physicians may need to choose between treatment efficacy and the invasiveness of certain methods of administration (such as surgery or injection), both of which affect QoL. The method of treatment administration and its effect on QoL should be considered when developing new treatments for GA.

\section{EXPERIENCES OF BILL CASWELL AS A CARER}

Bill and Dolores Caswell have been married for 64 years. The next section of this review is driven by Bill's experiences after Dolores' diagnosis (in italics) and supported by the literature on caring for people with vision loss.

\section{It's a Fact of Life, and We Are Learning to Live with It}

Close to half of all people with vision loss make use of 'informal' care [65]. In Portugal, it is estimated that $390 \mathrm{~h}$ per informal carer, per annum, is spent caring for people with vision loss [65]. However, when vision loss approaches that of a person with GA (20/250 or worse), this can increase to $4892 \mathrm{~h}$ per carer per annum [66]-almost three times longer than a standard 37.5-h working week (1950 h/annum).

We recently moved to Vancouver, an unfamiliar area, which can pose challenges for those with vision loss; moving into a new residence is hard as other people may not understand our specific needs and could think Dolores is being cold towards them. Recently, we were on a crowded street and Dolores couldn't see me; she was very worried as she felt alone in strange surroundings-but I made sure she was never out of my sight. While the burden on carers can be substantial and is undeniable, and I do think I am a carer, I don't focus on that-it's just the way life is and we do a lot of things together.

I believe that Dolores' loss of vision has affected me less than if she became sight impaired earlier in her life; I think it is important to note that Dolores' situation is easier than for many people. If it had happened when we were younger, it would have had more influence on us. Overall, it's not a hardship for me, but a fact of life. Without doubt, it's a 
different commitment you've got to make to your partner.

Almost half of young people who care for their parents or other relatives report having a mental health issue and they miss considerably more days of higher education than those without caring responsibilities [67]. The impact of caring for parents on the reported mental health of middle-aged carers (50-58 years) is also substantial [68]. For some people, caring for a partner may have greater adverse effects on their mental health than caring for a parent [69].

The vital role of informal and often unpaid carers frequently passes unnoticed. However, it is crucial to provide support for people in these tiring, challenging situations.

\section{CURRENTLY AVAILABLE TECHNOLOGIES THAT MAY IMPROVE QOL IN GA}

Although there is currently no treatment for $\mathrm{GA}$, there are a number of technologies that may help people with GA to carry out daily tasks and engage with their hobbies. While there are some low-tech solutions to some issues associated with GA, such as colour-contrast chopping boards to help when chopping vegetables, information about modern technology is often difficult for older populations who are affected by GA to access. Below, we have collated some of the many technologies that are available to help people with GA.

The PenFriend is a device that allows people to attach 'audio labels' to items around the house, from washing instructions to colours, toiletries, spices and paperwork [70]. The most recent versions of the PenFriend also allow users to listen to audio books. At the time of writing, the Royal National Institute of Blind People (RNIB) PenFriend 3 was priced at $£ 95.99$ [70]. In addition, the RNIB website also stocks specially adapted recreational activities for people with vision loss, including tactile backgammon and chess sets, braille sudoku and automatic needle threaders.
There are also several applications on smartphones that can help people with vision loss-Siri (Apple) is a well-known smartphone assistant, but almost all smartphones come with some sort of proprietary assistant software nowadays (Samsung uses Bixby, Microsoft uses Cortana, Amazon uses Alexa and Google uses the Google Assistant). Smartphones and other voice-activated assistants can be used to play music, set calendar notifications, make phone calls, send texts, read out information present on the screen and more. The 'Be My Eyes' app connects people who are blind or have low vision with sighted volunteers who can provide visual assistance through a live video call: live volunteers can read menus, find street signs and respond to questions that require a greater degree of vision to answer. The 'Seeing Eye GPS' phone app (available in the USA and Canada) provides descriptive verbal navigation for people with low vision [71].

For those with vision loss who can read braille, there are options to connect braille keyboards and displays to computers, and some smartphones are compatible with braille tables and displays [72], allowing people to use braille to enter text (such as the 'TalkBack' braille virtual keyboard, available on Android and Apple devices). Standard computer keyboards can also be adapted with larger keys or high-contrast stickers to improve visibility.

Although magnifiers are not useful for all people with GA, especially those with more advanced vision loss, they remain a common and helpful aid for many. Many smartphones have inbuilt cameras capable of magnifying text and images 'live'. Furthermore, the recent move towards light detection and ranging (LiDAR) scanner technology means that some smartphones are now capable of detecting the proximity of an object, facilitating safe navigation around crowded spaces [72].

However, technological solutions can be expensive, with magnifiers and audio readers costing upwards of $£ 1000$ and apps requiring access to, and familiarity with, a smartphone. Depending on one's geographical location, there are schemes to loan such devices; this emphasises the vital role of support communities and accessibility to such groups. There are a 
number of support groups available for people with vison impairment. A select number of groups are summarised by geographical region in Table 1.

A major limiting factor for many people with GA is the lack of information about products or technologies that could assist in daily tasks; providing consistent and up-to-date information on currently available technology could vastly improve QoL for many people.

\section{UNMET NEEDS AND FUTURE PERSPECTIVES ON QOL IN GA}

\section{Current Unmet Needs For Patients With GA}

GA has a notable disease burden for patients. The loss of vision can be traumatic and impacts many aspects of a patient's life, including social relationships, hobbies and daily activities. Although there are schemes and technologies that can support patients with GA, many patients may not be aware of them. Support systems may be inadequate or, in some cases, unavailable, to patients with a new diagnosis of GA; patients must often find resources themselves, which can be particularly challenging if they are isolated. It is clear that greater access to information about GA is fundamental to improving patient QoL. While at present there is no approved treatment for GA, involving and informing people with GA about the process of retinal health research may improve outcomes for both patients and researchers.

\section{Current Unmet Needs For Physicians Treating GA}

Physicians lack a consistent framework to guide and help patients with GA post-diagnosis, and there is local variation in the extent of support available. Some professional bodies, such as the Royal College of Ophthalmologists, recommend offering 'low vision' support to patients with GA if vision loss is impacting upon their independence and lifestyle at the time of

Table 1 Select list of support groups for people with vision impairment

\begin{tabular}{|c|c|c|}
\hline Support group & Location & Website \\
\hline Royal National Institute of Blind People (RNIB) & UK & https://www.rnib.org.uk/ \\
\hline Macular Society & UK & $\begin{array}{l}\text { https://www. } \\
\text { macularsociety.org/ }\end{array}$ \\
\hline Canadian National Institute for the Blind (CNIB) & Canada & https://www.cnib.ca/ \\
\hline Deutscher Blinden und Sehbehindertenverband (DBS) & Germany & https://www.dbsv.org/ \\
\hline Pro RETINA & Germany & $\begin{array}{l}\text { https://www.pro-retina. } \\
\text { de/ }\end{array}$ \\
\hline Spanish National Organisation of the Blind (ONCE) & Spain & http://www.once.es \\
\hline American Foundation for the Blind (AFB) & USA & https://www.afb.org/ \\
\hline National Federation of the Blind (NFB) & USA & https://www.nfb.org/ \\
\hline European Blind Union (EBU) & Europe & $\begin{array}{l}\text { http://www.euroblind. } \\
\text { org/ }\end{array}$ \\
\hline $\begin{array}{l}\text { International Council for Education and Rehabilitation of People with Visual } \\
\text { Impairment (ICEVI) }\end{array}$ & Europe & $\begin{array}{l}\text { http://www.icevi-europe. } \\
\text { org/ }\end{array}$ \\
\hline African Union of the Blind (AFUB) & Africa & $\begin{array}{l}\text { http://www.afub-uafa. } \\
\text { org/ }\end{array}$ \\
\hline
\end{tabular}


diagnosis [73]; however, as patients may be discharged from care after their initial diagnosis, some will miss out on physician-facilitated access to low vision support as their condition worsens over time. A standardised framework should be developed to support post-diagnosis care for patients with GA, starting with increasing access and knowledge about community resources and technology. It is important that this framework includes a way for physicians to stay informed and in touch with their local vision impairment community, allowing them to easily refer their patients for accessible support options and to remain connected with developments beyond just the treatment of the disease. The impact of GA extends beyond the eye into the psychosocial aspects of health and wellbeing; although the clinical signs and symptoms of GA are similar across patients, the way in which GA affects a person's life will vary by individual. Training for physicians must continue to emphasise that patients with GA are not simply eyes that cannot be fixed-empathy, care and consideration for each person as a whole are vital.

\section{Future Perspectives}

The development of standardised programmes to improve access to technologies and support could greatly improve the QoL of patients with GA. The impact of GA (and other retinal diseases) extends far beyond the physiology of the eye, affecting mental health, physical ability and independence. Any standardised training or support programme must acknowledge the need to see beyond the eye. Critically, while support does exist for patients with 'low vision', there is local variation in the nature and availability of low vision services; integrating low vision support networks into standard care frameworks could help to improve the consistency, quality and accessibility of post-diagnosis support.

Furthermore, educational programmes could enhance physicians' understanding of the available options for their patients; it is crucial that such programmes target physicians of all experience levels and not just new doctors and researchers. Similar programmes should also be developed for patients, carers and the general public.

\section{CONCLUSIONS}

For QoL in GA to improve, physicians must be prepared to see beyond anatomy and consider patients holistically-looking beyond whether they can be 'treated' and focusing on how they can be supported. Promoting active dialogue between patients and physicians may help to build empathetic understanding and drive the development of programmes aiming to improve QoL for patients with GA. Furthermore, improving, developing and integrating educational programmes and workshops about GA for patients, carers physicians and the public alike would facilitate general understanding and awareness. These programmes could improve the confidence of patients, the knowledge of physicians and the ability of friends and family to support their loved ones with GA.

\section{ACKNOWLEDGEMENTS}

Funding. No funding or sponsorship was received for this review. The Rapid Service Fee was funded by Boehringer Ingelheim.

\section{Authorship and Author's Contribu-} tions. All named authors meet the International Committee of Medical Journal Editors (ICMJE) criteria for authorship for this article, take responsibility for the integrity of the work as a whole, and have given their approval for this version to be published. All authors were involved in the conception, drafting and reviewing of the manuscript.

Medical Writing, Editorial and Other Assistance. Medical writing support was provided by Dr Imogen Allred, DPhil, and Dr Tom Priddle, DPhil, of OPEN Health Communications and funded by Boehringer Ingelheim. The authors would like to acknowledge Fighting Blindness Canada. 
Disclosures. Dolores Caswell, William Caswell and Jill Carlton declare that they have no conflicts of interest.

Compliance with Ethics Guidelines. This article is based on previously conducted studies and does not contain any new studies with human participants or animals performed by any of the authors.

Data Availability. Data sharing is not applicable to this article as no datasets were generated or analysed during the current study.

Open Access. This article is licensed under a Creative Commons Attribution-NonCommercial 4.0 International License, which permits any non-commercial use, sharing, adaptation, distribution and reproduction in any medium or format, as long as you give appropriate credit to the original author(s) and the source, provide a link to the Creative Commons licence, and indicate if changes were made. The images or other third party material in this article are included in the article's Creative Commons licence, unless indicated otherwise in a credit line to the material. If material is not included in the article's Creative Commons licence and your intended use is not permitted by statutory regulation or exceeds the permitted use, you will need to obtain permission directly from the copyright holder. To view a copy of this licence, visit http://creativecommons.org/licenses/bync/4.0/.

\section{REFERENCES}

1. Barcaccia B, Esposito G, Matarese M, Bertolaso M, Elvira M, De Marinis MG. Defining quality of life: a wild-goose chase? Eur J Psychol. 2013;9:185-203.

2. WHO. WHOQOL: measuring quality of life. https:// www.who.int/mental_health/media/68.pdf. 1997. Accessed 9 Nov 2020.

3. Karnofsky DA, Burchenal JH. The Clinical Evaluation of Chemotherapeutic Agents in Cancer. In: MacLeod CM, editor, Evaluation of chemotherapeutic agents. New York: Columbia University Press; 1949. p. 196.
4. Spitzer WO, Dobson AJ, Hall J, et al. Measuring the quality of life of cancer patients: a concise QL-Index for use by physicians. J Chronic Dis. 1981;34(12): 585-97.

5. US Department of Health and Human Sciences, Centers for Disease Control and Prevention. Measuring healthy days: population assessment of health-related quality of life. Atlanta, Georgia: CDC; 2000. Available at: https://www.cdc.gov/ hrqol/pdfs/mhd.pdf.

6. Gabriel Z, Bowling ANN. Quality of life from the perspectives of older people. Ageing Soc. 2004;24(5):675-91.

7. Brown MM, Brown GC, Sharma S, et al. The burden of age-related macular degeneration: a value-based analysis. Curr Opin Ophthalmol. 2006;17(3): 257-66.

8. Bowling A, Stenner P. Which measure of quality of life performs best in older age? A comparison of the OPQOL, CASP-19 and WHOQOL-OLD. J Epidemiol Community Health. 2011;65(3):273-80.

9. Stevens K, Palfreyman S. The use of qualitative methods in developing the descriptive systems of preference-based measures of health-related quality of life for use in economic evaluation. Value Health. 2012;15(8):991-8.

10. Terwee CB, Prinsen CAC, Chiarotto A, et al. COSMIN methodology for evaluating the content validity of patient-reported outcome measures: a Delphi study. Qual Life Res. 2018;27(5):1159-70.

11. FDA. Principles for selecting, developing, modifying, and adapting patient reported outcome instruments for use in medical device evaluation. https://www.fda.gov/media/141565/download. Accessed 9 Nov 2020.

12. FDA. Patient-reported outcome measures: use in medical product development to support labeling claims. https://www.fda.gov/regulatoryinformation/search-fda-guidance-documents/ patient-reported-outcome-measures-use-medicalproduct-development-support-labeling-claims. 2009. Accessed 9 Nov 2020.

13. Post MW. Definitions of quality of life: what has happened and how to move on. Top Spinal Cord Inj Rehabil. 2014;20(3):167-80.

14. Handa JT, Bowes Rickman C, Dick AD, et al. A systems biology approach towards understanding and treating non-neovascular age-related macular degeneration. Nat Commun. 2019;10(1):3347.

15. Molday RS, Moritz OL. Photoreceptors at a glance. J Cell Sci. 2015;128(22):4039-45. 
16. Murakami Y, Notomi S, Hisatomi T, et al. Photoreceptor cell death and rescue in retinal detachment and degenerations. Prog Retin Eye Res. 2013;37: 114-40.

17. Boyer DS, Schmidt-Erfurth U, van Lookeren CM, Henry EC, Brittain C. The pathophysiology of geographic atrophy secondary to age-related macular degeneration and the complement pathway as a therapeutic target. Retina. 2017;37(5):819-35.

18. Boulton M, Dayhaw-Barker P. The role of the retinal pigment epithelium: topographical variation and ageing changes. Eye. 2001;15(3):384-9.

19. Moreira-Neto CA, Moult EM, Fujimoto JG, Waheed NK, Ferrara D. Choriocapillaris loss in advanced age-related macular degeneration. J Ophthalmol. 2018;2018:8125267.

20. Chakravarthy U, Bailey CC, Johnston RL, et al. Characterizing disease burden and progression of geographic atrophy secondary to age-related macular degeneration. Ophthalmology. 2018;125(6): 842-9.

21. Brader HS, Ying GS, Martin ER, Maguire MG. Characteristics of incident geographic atrophy in the complications of age-related macular degeneration prevention trial. Ophthalmology. 2013;120(9):1871-9.

22. Wells-Gray EM, Choi SS, Bries A, Doble N. Variation in rod and cone density from the fovea to the midperiphery in healthy human retinas using adaptive optics scanning laser ophthalmoscopy. Eye (Lond). 2016;30(8):1135-43.

23. Finger RP, Wu Z, Luu CD, et al. Reticular pseudodrusen: a risk factor for geographic atrophy in fellow eyes of individuals with unilateral choroidal neovascularization. Ophthalmology. 2014;121(6): 1252-6.

24. Wightman AJ, Guymer RH. Reticular pseudodrusen: current understanding. Clin Exp Optom. 2019;102(5):455-62.

25. Sadda SR, Chakravarthy U, Birch DG, Staurenghi G, Henry EC, Brittain C. Clinical endpoints for the study of geographic atrophy secondary to age-related macular degeneration. Retina. 2016;36(10): 1806-22.

26. Agrón E, Mares J, Clemons TE, Swaroop A, Chew EY, Keenan TDL. Dietary nutrient intake and progression to late age-related macular degeneration in the age-related eye disease studies 1 and 2 . Ophthalmology. 2020;128:425-42.

27. Williams RA, Brody BL, Thomas RG, Kaplan RM, Brown SI. The psychosocial impact of macular degeneration. Arch Ophthalmol. 1998;116(4): 514-20.

28. Sunness JS, Bressler NM, Tian Y, Alexander J, Applegate CA. Measuring geographic atrophy in advanced age-related macular degeneration. Invest Ophthalmol Vis Sci. 1999;40(8):1761-9.

29. Carlton J, Barnes S, Haywood A. Patient perspectives in geographic atrophy (GA): exploratory qualitative research to understand the impact of GA for patients and their families. Br Ir Orthopt J. 2019;15(1):133-41.

30. Sivaprasad S, Tschosik EA, Guymer RH, et al. Living with geographic atrophy: an ethnographic study. Ophthalmol Ther. 2019;8(1):115-24.

31. Burguera-Gimenez N, Garcia-Lazaro S, Espana-Gregori E, et al. Multimodal evaluation of visual function in geographic atrophy versus normal eyes. Clin Ophthalmol. 2020;14:1533-45.

32. Taylor DJ, Smith ND, Binns AM, Crabb DP. The effect of non-neovascular age-related macular degeneration on face recognition performance. Graefes Arch Clin Exp Ophthalmol. 2018;256(4): 815-21.

33. Sunness JS, Gonzalez-Baron J, Applegate CA, et al. Enlargement of atrophy and visual acuity loss in the geographic atrophy form of age-related macular degeneration. Ophthalmology. 1999;106(9): 1768-79.

34. Varma R, Souied EH, Tufail A, et al. Maximum reading speed in patients with geographic atrophy secondary to age-related macular degeneration. Investig Ophthalmol Vis Sci. 2018;59(4): AMD195-201.

35. Patel PJ, Ziemssen F, Ng E, et al. Burden of illness in geographic atrophy: a study of vision-related quality of life and health care resource use. Clin Ophthalmol. 2020;14:15-28.

36. Goldstein JE, Fenwick E, Finger RP, et al. Calibrating the impact of vision impairment (IVI): creation of a sample-independent visual function measure for patient-centered outcomes research. Transl Vis Sci Technol. 2018;7(6):38.

37. Sacconi R, Corbelli E, Querques L, Bandello F, Querques G. A review of current and future management of geographic atrophy. Ophthalmol Ther. 2017;6(1):69-77.

38. Danis RP, Lavine JA, Domalpally A. Geographic atrophy in patients with advanced dry age-related macular degeneration: current challenges and future prospects. Clin Ophthalmol. 2015;9: 2159-74. 
39. Roh M, Selivanova A, Shin HJ, Miller JW, Jackson ML. Visual acuity and contrast sensitivity are two important factors affecting vision-related quality of life in advanced age-related macular degeneration. PLoS ONE. 2018;13(5):e0196481.

40. Sunness JS, Rubin GS, Applegate CA, et al. Visual function abnormalities and prognosis in eyes with age-related geographic atrophy of the macula and good visual acuity. Ophthalmology. 1997;104(10): 1677-91.

41. Klein R, Wang Q, Klein BE, Moss SE, Meuer SM. The relationship of age-related maculopathy, cataract, and glaucoma to visual acuity. Invest Ophthalmol Vis Sci. 1995;36(1):182-91.

42. Patino CM, McKean-Cowdin R, Azen SP, Allison JC, Choudhury F, Varma R. Central and peripheral visual impairment and the risk of falls and falls with injury. Ophthalmology. 2010;117(2):199-206.e1.

43. Minto $H$, Butt IA. Low vision devices and training. Community Eye Health. 2004;17(49):6-7.

44. Singh A, Sørensen TL. The prevalence and clinical characteristics of Charles Bonnet Syndrome in Danish patients with neovascular age-related macular degeneration. Acta Ophthalmol. 2012;90(5): 476-80.

45. Kumar B. Complex visual hallucinations in a patient with macular degeneration: a case of the Charles Bonnet syndrome. Age Ageing. 2013;42(3): 411.

46. Nixon PA, Mason JO III. Visual hallucinations from age-related macular degeneration. Am J Med. 2006;119(3):e1-2.

47. Avery SN, VanDerKlok RM, Heckers S, Blackford JU. Impaired face recognition is associated with social inhibition. Psychiatry Res. 2016;236:53-7.

48. Brown JC, Goldstein JE, Chan TL, Massof R, Ramulu P. Characterizing functional complaints in patients seeking outpatient low-vision services in the United States. Ophthalmology. 2014;121(8):1655-62.e1.

49. Stanford P, Waterman H, Russell WB, Harper RA. Psychosocial adjustment in age related macular degeneration. Br J Vis Impair. 2009;27(2):129-46.

50. Brunes A, Hansen BM, Heir T. Loneliness among adults with visual impairment: prevalence, associated factors, and relationship to life satisfaction. Health Qual Life Outcomes. 2019;17(1):24.

51. Rezapour J, Schuster AK, Nickels S, et al. Prevalence and new onset of depression and anxiety among participants with AMD in a European cohort. Sci Rep. 2020;10(1):4816.
52. Casten R, Rovner B. Depression in age-related macular degeneration. J Vis Impair Blind. 2008;102(10):591-9.

53. Augustin A, Sahel JA, Bandello F, et al. Anxiety and depression prevalence rates in age-related macular degeneration. Invest Ophthalmol Vis Sci. 2007;48(4):1498-503.

54. Nunokawa K, Seki Y, Ino S, Doi K. Judging hardness of an object from the sounds of tapping created by a white cane. In: Annu Int Conf IEEE Eng Med Biol Soc. 2014, pp 5876-9.

55. Hersh M. Cane use and late onset visual impairment. Technol Disabil. 2015;27:103-16.

56. Seybold D. The psychosocial impact of acquired vision loss-particularly related to rehabilitation involving orientation and mobility. Int Congr Ser. 2005;1282:298-301.

57. Ballemans J, Kempen GI, Zijlstra GR. Orientation and mobility training for partially-sighted older adults using an identification cane: a systematic review. Clin Rehabil. 2011;25(10):880-91.

58. Rindermann $\mathrm{H}$, Ackermann AL, te Nijenhuis J. Does blindness boost working memory? A natural experiment and cross-cultural study. Front Psychol. 2020;11:1571.

59. NCT02247479. A Study Investigating the Efficacy and Safety of Lampalizumab Intravitreal Injections in Participants With Geographic Atrophy Secondary to Age-Related Macular Degeneration (CHROMA). https://clinicaltrials.gov/ct2/show/ NCT02247479. Accessed 9 Nov 2020.

60. AVOCA. The AVOCA 2016 Patient Centred Survey: https://www.theavocagroup.com/wp-content/ uploads/2017/04/AQC-2016-Patient-CenteredSurvey-Report.pdf. 2016. Accessed 9 Nov 2020.

61. Biarnés M, Colijn JM, Sousa J, et al. Genotype- and phenotype-based subgroups in geographic atrophy secondary to age-related macular degeneration: the EYE-RISK Consortium. Ophthalmol Retina. 2020;4(12):1129-37.

62. Partridge $\mathrm{AH}$, Winer EP. Informing clinical trial participants about study results. JAMA. 2002;288(3):363-5.

63. Shingler SL, Bennett BM, Cramer JA, Towse A, Twelves C, Lloyd AJ. Treatment preference, adherence and outcomes in patients with cancer: literature review and development of a theoretical model. Curr Med Res Opin. 2014;30(11):2329-41.

64. Baxter JM, Fotheringham AJ, Foss AJ. Determining patient preferences in the management of 
neovascular age-related macular degeneration: a conjoint analysis. Eye (Lond). 2016;30(5):698-704.

65. Marques AP, Macedo AF, Hernandez-Moreno L, et al. The use of informal care by people with vision impairment. PLoS ONE. 2018;13(6):e0198631.

66. Köberlein J, Beifus K, Schaffert C, Finger RP. The economic burden of visual impairment and blindness: a systematic review. BMJ Open. 2013;3(11): e003471.

67. Becker S, Sempik J. Young adult carers: the impact of caring on health and education. Child Soc. 2019;33(4):377-86.

68. Solberg L, Solberg L, Peterson E. Measuring impact of stress in sandwich generation caring for demented parents. GeroPsych. 2014;4:171-9.

69. Hansen T, Slagsvold B. The psychological effects of providing personal care to a partner: a multidimensional perspective. Health Psychol Res. 2013;1(2):e25.

70. RNIB. PenFriend 3 Audio Labeller. https://www. rnib.org.uk/rnibconnect/technology/penfriend-3audio-labeller. Accessed 9 Nov 2020.

71. Sendero. The Seeing Eye GPS App. http://www. senderogroup.com/products/seeingeyegps/index. html. Accessed 9 Nov 2020.

72. iPhone. iPhone Vision Accessibility. https://www. apple.com/accessibility/iphone/vision/. Accessed 9 Nov 2020.

73. The College of Optometrists and The Royal College of Ophthalmologists: Commissioning Better Eye Care. https://www.rcophth.ac.uk/wp-content/ uploads/2014/12/AMD-guidance-25-11-13-2013 PROF_262.pdf. Accessed 9 Nov 2020. 